\title{
La Aplicación del Derecho Policivo en la ciudad de Neiva (2006 - 2007)
}

\author{
Semillero de investigación Scholla \\ Grupo Nuevas Visiones del Derecho \\ Vivian Lorena Falla, Ángela patricia Ruiz, Alicia Muñoz Cerón, \\ Maria Indyra Bravo, Anyela Paola Cardozo
}

Tutor: Dr. Germán Alfonso López Daza

\section{RESUMEN}

El presente artículo fue elaborado como parte de los resultados del proyecto de investigación sobre la aplicación del derecho policivo en la ciudad de Neiva durante el período 2006-2007. El derecho policivo cumple hoy día una importante función en las sociedades modernas debido a que constituye la función preventiva del Estado frente a la ciudadanía para lograr una mejor convivencia. Los resultados que presenta este artículo refleja la función que cumplen las inspecciones de policía en la ciudad de Neiva, buscando establecer cuales procesos tramitan, así como los resultados de tales procesos.

\section{PALABRAS CLAVE}

Derechos. Autoridad, seguridad, convivencia, comunidad y orden público.

\section{ABSTRACT}

This article was prepared as part of the results of the research project on policing law enforcement in the city of Neiva in the period 2006-2007. The police law meets an important role in modern societies because it is the preventive role of the state to the public for better coexistence. The results presented in this article reflects the role of police inspections in the city of Neiva, seeking to establish which processes handled and the outcome of such processes.

\section{KEYWORDS}

Police law, rights, authority, security, public order.

\section{INTRODUCCION}

La función preventiva del Estado, la seguridad ciudadana así como la promoción de un ambiente de convivencia pacífica para el desarrollo de la vida de los ciudadanos se realiza con la ayuda del derecho policivo.

Desde hace un tiempo, la cuestión relacionada con la seguridad de los ciudadanos y la convivencia ha tomado una importancia trascendental. Las políticas de convivencia ciudadana implementadas por el ex - alcalde de Bogotá Antanas Mockus, rescataron del olvido las numerosas normas de convivencia que se consideran incluidas en el denominado derecho policivo.

Esta rama del derecho contiene todas las normas, nacionales, departamentales y municipales, que establecen un orden ciudadano y posibilitan la 
convivencia pacífica. Tales normas policivas sancionan comportamientos ciudadanos reprochables, tales como botar basuras en lugares no indicados, hacer construcciones sin los permisos requeridos, emitir ruidos por encima de los parámetros señalados o contaminar el medio ambiente.

El derecho policivo es pues "un instrumento sistemático de normas que regulan imperativamente comportamientos humanos, con carácter coactivo o preventivo, y excepcionalmente correctivo, coercitivo o represivo ${ }^{\prime \prime}$, contando con una función comunitaria y de control de orden público, con la que busca dar cumplimiento al fin esencial del estado, el cual es la convivencia pacífica, el orden y la paz de la comunidad, basándose en "los medios y límites estatuidos en la Constitución Nacional, en la ley, en las convenciones y tratados internacionales, en el reglamento de policía y en los principios universales del derecho".

Teniendo en cuenta la función del derecho policivo así como sus características ${ }^{3}$, se dio inicio a la ardua investigación realizada en las diferentes inspecciones de policía de la ciudad de Neiva, con las dificultades propias de este tipo de investigaciones. Después de tramitar las correspondientes autorizaciones ante la Secretaría de Gobierno y la Dirección de Justicia Municipal, se seleccionaron de manera aleatoria, 160 procesos fallados durante los años 2006-2007, con el fin de establecer los tipos de procesos que se desarrollan en las inspecciones de policía así como su las decisiones tomadas.

El derecho policivo tiene su fuente constitucional en los artículos 216 y 218 de la Carta Política colombiana de 1991. Se encuentra regido a nivel nacional por el Decreto 1355 de 1970 en el que se expidió el Código Nacional de Policía, y a nivel departamental por el anterior Código Departamental de Policía (Decreto 1117 de 1988) y en la actualidad por el nuevo Manual de Convivencia Ciudadana del Departamento del Huila (Ordenanza 022 de 2008). Para efectos de esta investigación, el anterior Código Departamental de Policia estaba vigente en y era aplicado en los procesos policivos que se seleccionaron.

Tras la realización de esta investigación es posible esbozar un perfil jurídico del derecho policivo, respetuoso de los derechos humanos, comprensivo de los deberes ciudadanos, práctico a la hora de su aplicación y tramite, logrando asi mediante este, hacer viable el mandato constitucional del artículo 22 de la Carta, el cual expresa: "la paz es un derecho y un deber de obligatorio cumplimiento" Es este uno de los mecanismos más idóneos con los que cuenta el Estado para actuar como garante de la paz y la tranquilidad dentro del territorio nacional, objetivo básico que sigue esta importante rama del derecho. Además de verificar cómo se aplica el derecho policivo en la ciudad de Neiva, esta investigación podrá comprobar la realidad del proceso policivo dentro de las diferentes especialidades, además de poder utilizar los resultados arrojados para hacer un diagnostico sobre su funcionamiento y eficacia.

En este orden de ideas el llevar a cabalidad esta investigación no solo arrojó datos específicos, que nos llevaron a conocer la labor que han cumplido, están cumpliendo y posiblemente cumplirán las diferentes instituciones encargadas de asegurarle a la comunidad su convivencia pacífica, sino que se identificó si realmente siguen lo ordenado por los códigos Nacional y Departamental de Policia, estableciendo de esta manera el grado de eficacia de las inspecciones de policía en los diferentes conflictos que se ponen en su conocimiento.

\footnotetext{
${ }^{1}$ República de Colombia, Corte Suprema de Justicia, sentencia del 21 de Marzo de 2007.

${ }^{2}$ Ibid.

${ }^{3}$ Autonomía normativa, independencia procedimental y orgánica, carácter de previoy sumario, celeridad, normas de orden público, etc.
} 


\section{METODOLOGÍA}

Dadas las caracteristicas del estudio, obedece a un tipo de investigación de carácter cuantitativo como primera medida, en el sentido de que se buscó recoger y analizar datos numéricos sobre variables mediante la revisión de ciertos datos de los expedientes seleccionados. Previo a este ejercicio, se consultó toda la bibliografía encontrada la cual en cierta medida no es muy amplia, con el fin de sentar unas bases teóricas sobre el desarrollo teórico del derecho policivo. Asimismo, se determinó el procedimiento vigente a la hora de solucionar un conflicto de carácter policivo. Del mismo modo, se revisó la jurisprudencia de la Corte Constitucional y el Consejo de Estado para conocer la situación actual del derecho policivo, cómo ha sido su tratamiento y su procedimiento. Esta consulta jurisprudencial se organizó a través de la metodología de la línea jurisprudencial, la cual sirvió como sustento de la investigación. Ya para la revisión de los instrumentos, se aplicó una prueba piloto con el fin de determinar las variables del tema investigativo y conocer los datos más relevantes y de mayor incidencia. Se llevó a cabo la revisión de archivos, en la cual se sacó una muestra de 30 procesos por cada especialidad de las diferentes inspecciones con las que cuenta la ciudad de Neiva en los años 2006 y 2007. Con el fin de determinar la situación de los procesos archivados, verificar su procedimiento y si se cumplió lo ordenado por la normatividad sobre la materia.

Luego de la revisión de los archivos, se realizó la tabulación de la información obtenida con el objetivo de conocer estadísticamente el fenómeno. Aeste proceso de tabulación de la información se le llama distribución de frecuencias, y lo definimos como un método para organizar y resumir los datos en una tabla estadística. Con el fin de tener cada resultado en un orden específico con su respectiva gráfica y que de una u otra manera sea satisfactorio y de fácil acceso para el lector.

A pesar de haber utilizado el método cualitativo para llegar a los objetivos planteados, se hizo uso del método cualitativo pues se hizo un análisis de las variables, se realizaron registros narrativos de los asuntos o situaciones que fueron estudiado mediante técnicas como la observación y la realización de entrevistas en las inspecciones de la ciudad de Neiva, la cual se realizó a los funcionarios a través de preguntas que se propusieron y que se consideraron de vital importancia a la hora de darle veracidad a la investigación.

El objetivo de este ejercicio fue el de intercambiar información con los funcionarios y así poder despejar dudas o confirmar resultados que se habian obtenido. Además, sirvió para alcanzar un examen acerca de las necesidades y la posible manera de satisfacerlas. Por otra parte, la entrevista ofreció una excelente oportunidad para establecer una corriente de simpatía con el funcionanio, lo cual fue fundamental en el transcurso del estudio.

\section{MARCO TEÓRICO}

Desde los tiempos más remotos, el fin del Derecho Policivo, ha sido responder a la construcción y conservación de una sociedad justa, cumpliendo así con los fines esenciales del Estado de mantener el orden público, crear las condiciones necesarias para una convivencia pacífica, y procurar sus principales propósitos los cuales son el bienestar general de sus asociados y el hecho de contribuir a la paz de su comunidad.

A pesar que en su evolución el derecho policivo no haya sido visto como una rama independiente, el profesor Remberto Torres Rico (1999), sostiene que el carácter preventivo de los mandatos del derecho policivo para regular el orden, hacen que éste se predique como una especialidad en el tema, lo que lo convierte en un derecho autónomo $e$ independiente, por cuanto tiene su propio objeto de conocimiento acordado legalmente en el orden en su más mínima expresión, que es ese comportamiento mínimo exigidoa las personas que viven en comunidad para poder vivir en paz.

Su procedimiento es propio ya que generalmente es breve y sumario, con términos y etapas procesales sumamente cortos. De igual manera sostiene que la característica principal que lo 
diferencia de las demás ramas del derecho, es su manera preventiva de tratar el conflicto, a través del statu quo, puesto que es la decisión provisional utilizada en la orden de policía, que hace de él demostrar el interés en preservar el orden publico de la Nación.

De la misma manera como se ha dificultado encontrar la autonomía del derecho policivo, también lo ha sido el hecho de encontrar un concepto único y fundamentado que defina en su totalidad sus objetivos. Por su parte José Armando Ruiz Salazar (2007), sostiene la existencia de un concepto multívoco del derecho policivo, por cuanto tiene al menos cuatro significaciones diversas en el régimen constitucional colombiano. Enseña cuatro puntos de vista desde los que se puede percibir la noción de derecho policivo, esto dependiendo de la función que se esté cumpliendo, los cuales son: actividades ligadas a la preservación y restablecimiento del orden público, las actividades de las autoridades administrativas de policía, el cuerpo civil de funcionarios armados (Policia Nacional) y por último las autoridades judiciales que prestan sus servicios al esclarecimiento de delitos (Policía Judicial).

El concepto de derecho de policía surge en la época moderna, donde nace la necesidad de llevar a cabalidad el cumplimiento de los fines esenciales del Estado propuestos con la llegada del nuevo Estado Social de Derecho que tanta seguridad pretendia traer para la comunidad, esto buscándolo a través de un ente capaz de llenar las expectativas tanto del ciudadano como del Estado mismo, quien pretende cumplir con lo prometido. Es desde este punto de vista que la definición del concepto de derecho policivo se crea, siendo considerado como aquel conjunto o sistema de normas jurídicas que contienen una filosofía, unos principios y unos procedimientos con el fin de atribuir y permitir la realización de un derecho o una libertad, y excepcionalmente, limitar con sanciones o medios coercitivos especiales esos mismos derechos 0 libertades, en cuanto su ejercicio perturbe o pueda perturbar el orden, dentro de un estado social de derecho. (Torres, 1999 pag. 132).
Para determinar su origen, es importante saber que surgió gracias a la necesidad de la actividad humana y de su organización, la cual requería unos valores de subsistencia que le generaran mayor agilidad y seguridad a la hora de resolver sus conflictos, buscando el camino adecuado que condujera a dar orden a las actividades emprendidas por ella.

Por estos motivos, es importante conocer acerca de sus fuentes, puesto que son ellas quienes nos indican en realidad de donde proviene.

Como primera fuente tenemos la Constitución Política, siendo norma fundamental, que consagra los derechos y deberes de los ciudadanos, al igual que los principios que fundamentan el actuar del Estado; estableciendo de esta manera su importancia dentro de la creación del derecho de policía, ya que este tiene como objetivo el cumplimiento de los fines esenciales del Estado consagrados en nuestra Carta Política.

Es así, como se encuentra establecida la labor, el funcionamiento, las finalidades y objetivos del derecho policivo, en los artículos 216 a 223 de la Carta. El constituyente de 1991 también confirió poder de policía al Presidente de la República al concederle facultades legislativas extraordinarias $y$ transitorias en ejercicio de los poderes propios de los Estados de Excepción (guerra exterior, conmoción interior, emergencia económica ambiental y social) consagrados en los artículos 212 y siguientes de la Constitución.

De igual forma, to hizo al conferirle facultad de regulación por vía de los decretos reglamentarios consagrada en el artículo 189 numeral 11 de la Constitución Política. Así mismo, le otorgó a las Asambleas Departamentales poder de policía en el numeral 8 del artículo 300 al señalar que corresponde a dichas corporaciones reglamentar $l o$ relativo a la policía local en todo aquello que no sea materia de disposición legal. Por su parte el artículo 8 del Código Nacional de Policía establece que "las asambleas departamentales podrán hacerlo en relación con lo que no haya sido objeto de la ley 0 reglamento nacional". 
Al analizar la competencia de las asambleas en la sentencia C-024 de 1994, la Corte Constitucional colombiana sostuvo:

"Así, según la Constitución, a las asambleas departamentales mediante ordenanza les corresponde "dictar normas de policía en todo aquello que no sea materia de disposición legal, artículo 300 numeral 8 C.P., con lo cual se les confirió un poder de policía subsidiario."

Como segunda fuente, se encuentra la ley, la cual por disposición del artículo 150 numeral 2 de la Constitución Política, es competencia del Congreso expedir los códigos, entre ellos, el Código Nacional de Policía, competencia que es exclusiva toda vez que por mandato expreso del numeral 10 de la misma normatividad le está prohibido conceder facultades al Gobierno en estos temas.

En tercer término, y siguiendo con el respectivo análisis, se tiene como fuente del derecho policivo el reglamento, el cual es el acto jurídico general, impersonal y abstracto, dictado en ejercicio del poder reglamentario, atribuido a una autoridad administrativa (Torres, 1999 pag. 143).

Así las cosas, se tiene que la competencia reglamentaria de las asambleas departamentales en materia de policía está limitada por la Constitución y no procederá en asuntos con reserva legal, como lo relacionado con la libertad física y la regulación de la policía de tránsito, tal como lo establece el numeral 25 del artículo 150 de la Carta.

Igualmente, la propia Carta Política establece una competencia especíica a los concejos municipales en el artículo 313 numeral 9 al establecer que corresponde a dichas corporaciones dictar las normas necesarias para el control y defensa del patrimonio ecológico y cultural del Municipio.

Existen también facultades o habilitaciones expresas a las asambleas, como las contenidas en el propio Código Nacional de Policía artículo 180, el cual consagra competencia para reglamentar lo relativo a la prostitución sujetándose al Código Nacional ylos reglamentos del Gobierno Nacional.
De igual forma El Código Nacional de Policia le confirió facultades a los concejos municipales al establecerles competencia para regular el lugar y horario de los establecimientos que expenden bebidas alcohólicas (art. 111), seguridad e higiene de locales de comercio (art. 113), lugar de funcionamiento de los depósitos de explosivos y materiales inflamables (art. 114), las ventas ambulantes (art. 116), la ubicación de fabricas y comercios, entre otros temas.

Es por esto que con el objetivo de determinar el alcance con el que cuenta el Decreto 1117 de 1998 (Código Departamental de Policía del Huila), se definió como una línea de investigación dentro del marco jurídico de la investigación realizada por el Semillero de Investigación SCHOLLA, la determinación de la competencia de la Asamblea departamental, Ilegandoa la siguiente conclusión:

Se puede regular:

- Libertad de comercio e industria (art. $108 \mathrm{CNP}$ )

- Prostitución (art. 180 CNP)

- No haya sido objeto de ley (art. 8CNP)

- No sea reserva legal (art. 300-8 CN)

No se pueden regular:

- Policía de tránsito (art. 150-25 CN)

- Patrimonio ecológico y cultural (art. 323-9 CN)

- Usos del suelo (art. 313-7 CN)

- Lugaryhorario del expendio de bebidas alcohólicas (art. $111 \mathrm{CNP}$ )

- Seguridad e higiene de locales de comercio y establecimiento público (art. $313 \mathrm{CNP}$ )

- Depósito de explosivos y materiales inflamables (art. 114 CNP)

- Ventas ambulantes (art. 116 CNP)

- Laubicación de fábricas y decomercios (art. 121 CNP)

- No pueden crear medidas correctivas.

- Control poblacional (ley 47 de 1993 art. 10).

Continuando con el análisis, se tiene la jurisprudencia como otra de las fuentes, que a lo largo de la historia ha brindado su granito de arena en la creación y fortalecimiento del derecho policivo como rama del derecho. Es esta la que lleva a determinar que el Derecho de Policía es una fuente 
Gráfico No. 1

\section{TIPO DE CONTRAVENCIÓN}

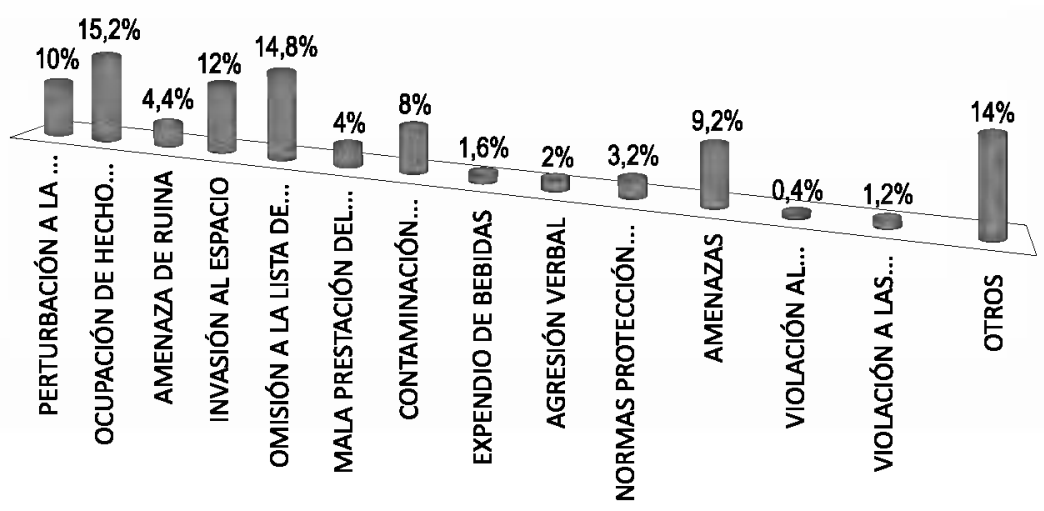

indirecta por cuanto no existe un juez de policía, de carácter jurisdiccional, que dirima conflictos de policía, con tránsito a cosa juzgada y por ello en la medida que una sentencia oriente la actividad policial será fuente indirecta (Torres, 1999 pag.144).

Las última de las fuentes a nombrar son la doctrina y la costumbre, las cuales no son del todo fuentes directas que aporten en gran medida a la creación del derecho policivo, pero que en parte colaboran, bien sea por medio de aportes de importantes doctrinantes que sirven para la construcción 0 corrección de las normas o por la creación de normas de carácter local que generan diferencias fundamentales en cada espacio, siendo creadas conforme a los hábitos adquiridos de cada región.

Como se puede deducir de todo lo anterior, el derecho de policía tiene desde sus inicios la labor de darle a la comunidad el bienestar, la seguridad y la salubridad basados todos en el propósito y único fin de conseguir para el país entero, sin importar distinción de costumbre o región, la convivencia pacífica necesaria para vivir adecuadamente en paz y armonía ciudadana.

\section{RESULTADOS}

La siguiente información fue adquirida por medio de la aplicación de los instrumentos en la recolección de los datos de las inspecciones de policía en la ciudad de Neiva.

De acuerdo a esta gráfica, se puede analizar los tipos de contravenciones, que usualmente se presentan en las inspecciones de policía de la ciudad de Neiva.

En primer lugar, se encuentra el lanzamiento por ocupación de hecho como la contravención que refleja mayor porcentaje dentro de la investigación llevada a cabo, con una cifra arrojada del 15,2\%, lo que indica la actual situación por la que está pasando la ciudad, ya que representa entre otros problemas el desplazamiento forzoso, fenómeno que afecta en la actualidad a todo el territorio nacional.

Esta contravención tiene su origen en problemas tanto económicos como sociales, entre lo que se puede enunciar el desplazamiento forzado, la pobreza extrema y los altos índices de desempleo, 
que hacen que las personas busquen un sitio adecuado para poder habitar con su familia, invadiendo terrenos privados sobre los cuales no tienen posesión alguna.

Como consecuencia de lo anterior, existe un proceso a través del cual se pone fin a la ocupación arbitraria de un inmueble y se restituye su tenencia a favor del tenedor legítimo. No obstante al adelantarse por funcionarios de policía, es un caso particular en el que autoridades administrativas cumplen funciones judiciales, ateniéndose a una legislación especial y en el que la sentencia que se profiere hace tránsito a cosa juzgada formal y no es cuestionable ante la jurisdicción de lo contencioso administrativo.

Se trata así, de un proceso de partes en el que una de ellas maneja la pretensión de lanzamiento y la otra se opone a él aportando pruebas que legitimen su estadía en el inmueble invadido. Esa tensión es resuelta por la autoridad de policía y debe hacerlo valorando los elementos de juicio aportados a la querella y aquellos recaudados durante la misma diligencia de lanzamiento; infiriendo si están o no satisfechas las exigencias sustanciales impuestas por la ley y emitiendo una decisión motivada, apegada al ordenamiento jurídico y consistente con las pruebas practicadas. (Corte Constitucional sentencia T-093/06 M.P. Jaime Córdoba)

En segundo lugar, se encuentra la omisión a la lista de precios, con un indice del $14,8 \%$ del total de los procesos analizados, infracción cometida principalmente en tiendas de barrio, almacenes, y los llamados mini mercados. Se infiere que esta contravención se comete usualmente por los propietarios de esos establecimiento por falta de conocimiento de la norma y de esta manera se hacen acreedores de sanciones como multas hasta dos millones de pesos $(\$ 2.000 .000 .00)$ de acuerdo con la capacidad económica del infractor y la gravedad del hecho, decomiso de los productos 0 artículos que han sido objeto de especulación o acaparamiento, arresto inconmutable hasta por treinta (30) días, cierre del establecimiento industrial o comercial hasta por treinta (30) dias y cancelación definitiva de la licencia de funcionamiento industrial o comercial del infractor.

En tercer lugar, está la invasión del espacio público con un porcentaje del $12 \%$. La manifestación típica de esta contravención se observa especialmente entre el ciudadano y su vecino; un ejemplo de esta situación se encuentra en el típico caso de aquellas tiendas que se instalan con mesas y sillas en lugares destinados para el tránsito de las personas, como lo es el andén, generando problemas con los peatones que deseen pasar por el lugar; en estos casos muchas veces el peatón decide arriesgar su vida circulando fuera del sector y evitar molestias con el dueño de la tienda. Estos casos se pueden impulsar en la inspección de Control Urbano, ya que el ciudadano está en la obligación de denunciar cualquier atropello cometido contra la comunidad.

Entre los más bajos porcentajes se encuentran la violación a las normas de funcionamiento con el $1,2 \%$, consistente en la infracción cometida por establecimientos comerciales abiertos o no al público los cuales deben cumplir con ciertos requisitos, entre los cuales están la hora del cierre del lugar, prohibir el ingreso y expendio de bebidas alcohólicas a menores de edad, la cual es otra de las contravenciones que se presenta en la ciudad con el $1,6 \%$ de casos analizados, el respetar los niveles de audición señalados por la ley, siendo esta otra de las contravenciones existente bajo el nombre contaminación auditiva, la cual se manifiesta con un $8 \%$ de incidencia, generada por tiendas y almacenes que utilizan medios de publicidad sonoros más altos de lo permitido, generando disgusto en la comunidad.

Las normas establecidas por la legislación colombiana expresan: está prohibido el ruido que supere los niveles permitidos, esto de acuerdo al sector, establecido según el plan de ordenamiento territorial de la ciudad, además del generado por parlantes o bafles en espacio público, el perifoneo y el pregoneo realizado por payasos o anunciantes de productos por megáfono, micrófono o parlantes en vehículos; y aquellas otras actividades contempladas en articulo 82 del Código Nacional de Policía. 
Gráfico No. 2

FECHA SOLICITUD DEL SERVICIO V.S. FECHA DE INICIO

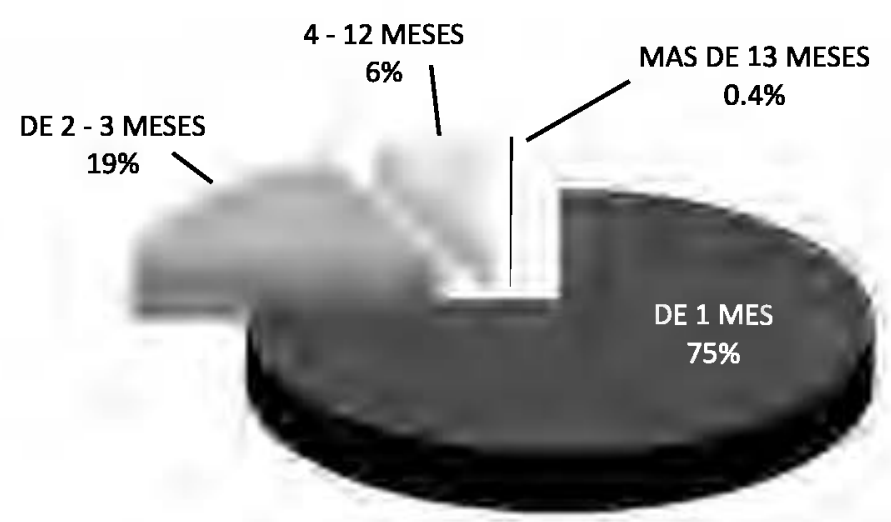

Al hablar de generación de ruido de forma continua por parte de establecimientos comerciales abiertos al público como bares, tiendas, rockolas, almacenes de venta de diferentes productos, supermercados, entre otros, se debe acudir a quien tiene la competencia de controlar y tramitar las perturbaciones por ruido por parte de establecimientos comerciales, sin embargo si el ruido generado está afectando adversamente a las personas, se puede de inmediato solicitar intervención de la Policía quien deberá acudir prontamente al lugar y solicitar el cumplimiento de las normas de convivencia a los infractores.

Con el $9,2 \%$ se encuentran las amenazas, contravención que se puede relacionar con las agresiones verbales las cuales presentan el $2 \%$. Estos son problemas relacionados con todas las contravenciones anteriores, dada la complejidad de la problemática, muchas veces se llega a los extremos y utilizando la violencia. En estos casos, los ciudadanos no tienen en cuenta un mecanismo alterno para la solución de conflictos, decidiendo por el contrario ejercer el control por su propia cuenta. Muchas de estas contravenciones fueron de traslado por parte de la fiscalía, siendo remitidas a las inspecciones de policia urbana por ser problemas de convivencia ciudadana. Además, es importante resaltar que en su mayoría, en estas querellas no hubo citación a las partes.
Por último en lo referente a la gráfica número uno, el $4,4 \%$ le corresponde a las contravenciones comunes -amenaza de ruina- cuyo objetivo es suprimir el peligro que representa para los ciudadanos un inmueble en mal estado, ocurriendo principalmente por el descuido de su propietario al hacer mejoras al bien, para evitar posibles amenazas de destrucción. Este proceso se puede iniciar de oficio o por petición de parte.

En el gráfico número 2, se indica el tiempo transcurrido desde la solicitud del servicio hasta la iniciación del proceso. Se observa que el porcentaje más alto está en la iniciación de las actuaciones en el mes en que se solicitó el servicio; esto demuestra que los funcionarios encargados de aplicar el derecho policivo están actuando con diligencia, celeridad y eficacia. Siendo un derecho fundamental de todo ciudadano el acceder a la administración de justicia, implica que su demanda sea resuelta de forma imparcial, efectiva y prudente. Para lograr este objetivo es necesario que la autoridad competente asuma el compromiso de resolver en forma diligente y oportuna los conflictos sometidos a su conocimiento dentro del plazo que defina el legislador. Por esta razón, se considera que es parte importante del derecho al debido proceso y de acceder a la administración de justicia, el que las personas tengan un proceso ágil y sin retrasos indebidos. 
Gráfico No. 3

FECHA SOLICITUD DEL SERVICIO

V.S. FECHA DECISIÓN DEFINITIVA

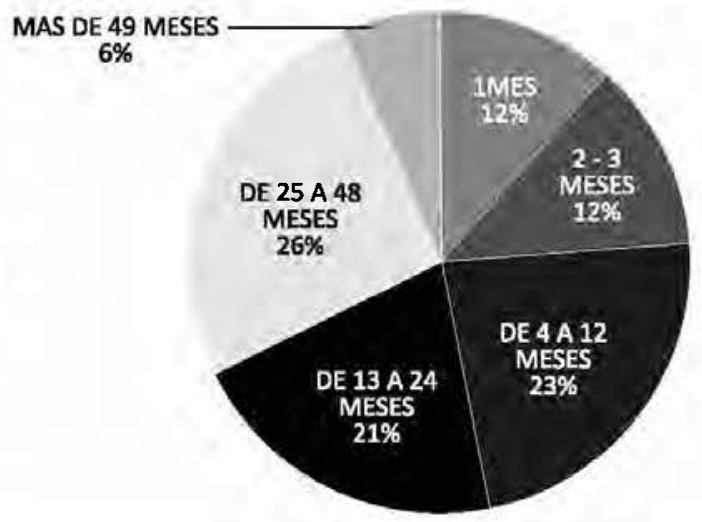

Sin embargo esta eficacia de las inspecciones de policía, se cumple de manera parcial, ya que se encuentra un menor porcentaje de querellas que se iniciaron de dos a tres meses después, como también de cuatro a doce meses y un mínimo de más de trece meses. Esto demuestra que es aceptable la aplicación de la norma policiva, puesto que falta fortalecer un poco para que se tenga una plena eficacia el derecho policivo.

La grafica numero 3 hace referencia al tiempo transcurrido desde la fecha de solicitud del servicio hasta la fecha de la decisión definitiva, de la que se puede inferir el deficiente servicio que brindan las inspecciones de policía a la hora de la preservación del orden público, de la seguridad de la comundad y la solución de conflictos pronta yoportunamente.

La anterior afirmación se fundamenta en que los datos analizados nos arrojan como resultado que la mayoría de los casos tardan de veinticinco (25) a cuarenta y ocho (48) meses para proferir su decisión, causando que el hecho materia de contravención, desaparezca antes de la toma de la decisión, situación que causa un mayor impacto ala comunidad pues atenta con el principio de celeridad que rige a todas las actuaciones procesales y confianza en la administración de justicia.

Finalmente cabe destacar que hay procesos que tardan de trece (13) a veinticuatro (24) meses, tiempo que es aceptable en alguno de los casos para emitir la resolución definitiva, pero que de todas maneras se encuentran en un tiempo medio para el pronunciamiento de la decisión.

\section{CONCLUSIONES}

El derecho policivo ha actuado como mecanismo de solución de problemas latentes en nuestra sociedad como son la ocupación de hecho, la invasión del espacio público, las amenazas, la contaminación auditiva, entre otras faltas a la convivencia ciudadana, las cuales no han tenido una solución adecuada por la carencia de políticas públicas por parte de la Dirección de Justicia Municipal y el Gobierno municipal, reflejando que el derecho policivo no se está desarrollando a cabalidad, confirmando así su ineficacia a la hora de brindarle justiciaa la comunidad.

El derecho policivo a través de las inspecciones de policía, debe actuar como garante de la solución de los distintos problemas latentes de la sociedad, utilizando mecanismos eficaces para tal fin pues son las normas del derecho policivo el medio idóneo para la realización de los fines del Estado consagrados en el Preámbulo y articulo $2^{\circ}$ de la Constitución Política.

El derecho policivo ha evolucionado y se desarrolla de acuerdo a las necesidades de cada sociedad, teniendo en cuenta que es un derecho que va de la 
mano con la comunidad y que está instituido con el fin de garantizar una convivencia pacífica de los ciudadanos.

Los conflictos que se presentan con mayor frecuencia en la ciudad de Neiva son el reflejo directo de los fenómenos que se han originado a raíz del conflicto armado en nuestro país. Un ejemplo claro de ello es que dentro de todos los procesos revisados, el mayor número de querellas fueron presentadas por la ocupación de hecho con un $17,22 \%$, lo que podría explicarse con el fenómeno creciente del desplazamiento forzado. Las personas víctimas de este flagelo, ocupan predios que en su momento encuentran abandonados, pero que posteriormente aparecen sus dueños a reclamar la posesión de los mismos.

Otro de los problemas que se agudizan cada día más en la ciudad es la invasión del espacio público, pues el total de casos presentados por esta contravención dio un porcentaje total de $16,11 \%$ de todos los procesos estudiados. Esto muestra una clara falla de los Gobiernos municipal y departamental en la implementación de políticas públicas, y lo que afecta claramente los derechos de los ciudadanos al goce libre del espacio público, el cual raya directamente con el derecho al trabajo alegado por los vendedores ambulantes, situación que amerita una pronta solución por parte de las autoridades competentes, ya que hasta el momento desde las inspecciones de policía no se ha logrado hacer nada, pues sus decisiones son superfluas y nunca se hace un seguimiento directo para verificar se cumplan las sanciones interpuestas por ellos y además que no se repita esta situación. Esta situación se ha convertido en un problema social que se acentúa ante la indiferencia que muestra el gobierno municipal.

Teniendo en cuenta las contravenciones de mayor frecuencia que se presentan en las inspecciones de la ciudad de Neiva, las autoridades no han tomado medidas pertinentes concernientes a garantizar el cumplimiento de las normas de urbanismo, ya que el número de casos que se presentan es muy elevado sin tener en cuenta aquellos casos que la comunidad no da a conocer a las autoridades.
Respecto al análisis de las fechas de solicitud del servicio en los procesos archivados y la fecha de inicio de la actuación del funcionario, el $25.6 \%$ de los procesos duró en iniciarse un mes después de la solicitud interpuesta por el ciudadano, demostrando la ineficacia y el incumplimiento de los funcionarios a la hora de brindar soluciones agiles a la comunidad.

Con la fecha de la decisión definitiva, se observa que el resultado arrojado es que existen casos en los cuales las actuaciones de las inspecciones de policía de la ciudad de Neiva tardan mucho tiempo en dar la decisión definitiva a la contravención, ya que el $26 \%$ de los procesos archivados, duró de veinticinco a cuarenta y ocho meses, lo que nos conduce a pensar que las inspecciones de la ciudad de Neiva se están acercando cada vez más a los términos procesales de la justicia ordinaria, incumpliendo con su fin de creación, el cual es solucionar conflictos menores de manera rápida, con lo cual se confirma además de lo ya mencionado el alto grado de ineficacia del derecho policivo en la ciudad de Neiva teniendo en cuenta el Código y Manual de Convivencia Ciudadana.

Lo anteriormente descrito da los argumentos suficientes para sostener que las inspecciones de policia hasta hoy en día no están cumpliendo con sus funciones a cabalidad, lo cual va en detrimento de los derechos de las personas; ya que éstas acuden ante las autoridades con el fin de buscar que se les brinde una solución a sus problemas y el tiempo que tardan las mismas en resolver la situación de fondo es demasiado, lo cual genera una ineficacia en la aplicación de las normas de derecho policivo y una desconfianza de la comunidad en si existen o no unos verdaderos mecanismos capaces de garantizar el goce de sus derechos y libertades, o si por el contrario las entidades encargadas de colocar en funcionamiento éstos mecanismos son negligentes.

El haber realizado entrevistas a los funcionarios de las inspecciones de policia da un marco de referencia que ayuda a sostener que a pesar de que existen muchos conflictos en la comunidad, los 
ciudadanos no acuden a denunciarlos lo que hace más difícil la aplicación del derecho policivo. Esto fue constatado con los mismos funcionarios de las inspecciones de policía quienes sostuvieron que a ellos se acude muy poco, por lo cual se ve una imperante necesidad de educar a la comunidad en general para que acudan a las normas del derecho policivo con el fin de solucionar sus diversos conflictos.

Otra de las deficiencias que se reconocen tras la investigación realizada es que las entidades encargadas de aplicar las normas de derecho policivo no brindan un buen servicio a la comunidad, lo cual se convierte en una debilidad pues las personas al no encontrar una respuesta amable cuando acuden ante estas autoridades, deciden actuar por su propia cuenta, rompiendo asi el equilibrio del que debe gozar la sociedad para poder funcionar.

Por otra parte el vacío más grande que se encuentra, es el lapso que transcurre entre la fecha en que se acude las inspecciones de policía y la fecha que se obtiene una solución definitiva del conflicto que se ha puesto en conocimiento pues se encontraron procesos que duran más de 2 años siendo este un término exagerado, a sabiendas que los proceso que constituyen el derecho policivo deber ser sumarios de rápida solución. Este aspecto hace que la solución de los problemas de los individuos sea caótica y además implica un desgaste de los accionantes, mientras que la ley dice que es un mecanismo de fácil acceso y rápida solución en la practica la cuestión es eminentemente diferente y se incumplen por tal razón los ordenamientos de carácter nacional y departamental; no solo esto sino que en los casos en que involucren derechos fundamentales se vulnera la misma Constitución Política.

Después del análisis de los resultados arrojados por la investigación realizada, se cree que es urgente que tanto el Gobierno Municipal como el Departamental, entre a supervisar el funcionamiento de las inspecciones de policía de una manera minuciosa y a tomar las medidas que crea pertinentes para poder garantizar el correcto funcionamiento del aparato estatal desde las inspecciones de policía de nuestra ciudad, para poder garantizar a los ciudadanos un verdadero goce de sus derechos y libertades.

\section{RECOMENDACIONES}

La experiencia investigativa arroja necesariamente algunas recomendaciones tendientes a enfrentar algunos de los múltiples problemas que aquejan la administración de justicia municipal. Entre otros se pueden citar:

- Educar a los usuarios de las inspecciones de policía y a la comunidad en general de la ciudad de Neiva, mediante la realización de campañas para ampliar el conocimiento acerca del derecho policivo, el cual es de gran importancia para la convivencia ciudadana.

- Capacitar a los funcionarios de las inspecciones de policía para que estos cumplan a cabalidad sus funciones y de esta manera mejoren la prestación del servicio.

- Adoptar políticas públicas tendientes a que se garanticen y reconozcan los derechos y deberes tanto de los funcionarios como los de la comunidad.

- Reconocer la importancia del derecho policivo en la comunidad, para poder solucionar aquellos conflictos de menor relevancia jurídica, como son las contravenciones para poder prevenir una futura consumación de delitos.

- Brindar a los funcionarios todas las herramientas necesarias y adecuadas para entrar en contacto con la comunidad y de una manera pacífica conocer sus necesidades ylas posibles soluciones.

- Crear mecanismos de participación ciudadana para que la comunidad intervenga en las actuaciones de los funcionarios y de esta manera cumplan con sus funciones y deberes a cabalidad.

- Encomendar al gobierno departamental el llevar a cabo un análisis de esta investigación para que de 
esta manera establezca los motivos de la ineficacia existente en algunas de las inspecciones de policía y poder brindar un mejor servicio a los ciudadanos que acudan a esta institución.
- Invitar a la dirección de justicia y a la Alcaldía Municipal a dar un buen manejo de los procesos archivados facilitando así el trabajo de futuras investigaciones.

\section{BIBLIOGRAFÍA}

- Código Nacional de Policía (Decreto 1355 de 1970)

- Código Departamental de Policía (Decreto 1117 de 1988), Huila.

- Constitución Política de Colombia (1991)

- Illera, María de Jesus. Convivencia y Cultura Ciudadana: dos pilares fundamentales del derecho policivo. Revista de Derecho Universidad del Norte 23: 240-259, 2005.

- Londoño J. (1996) Derecho de policía. Medellín Antioquia Colombia. Editorial Medellín y Abogados, Librería.

- Manual de Convivencia Ciudadana, (Ordenanza 022 de 2007), Huila.

- Corte Suprema de Justicia, sentencia del 21 de Marzo de 2007, M. P. Dr. Espinosa S. Acta No 42

- M.P Dr. Córdoba J. Sentencia T-093 (10 de Febrero de 2006), Bogotá D.C. Colombia. Corte Constitucional.

- Ruiz J.A. (2007) Derecho Policivo. Bogotá, D.C. Colombia: Editorial LEYER

- Ruiz J.C; Illera O; Manrique V. La tenue línea de la tranquilidad, estudio comparado sobre la seguridad ciudadana y policía

- Torres R. (1999).Tratado de derecho de policía. Bogotá D.C. Colombia. Ediciones Ciencia y Derecho. 